\title{
Gastro-oesophageal Reflux after Partial Gastrectomy
}

\author{
COLIN W. O. WINDSOR,* м.в., CH.B., F.R.C.S.
}

Gastro-oesophageal reflux following partial gastrectomy, giving rise to severe oesophagitis and stricture formation, has been described by several authors (Bingham, 1958; McKeown, 1958 ; Benedict, 1960 ; Cox, 1961). Below it is suggested that less severe symptoms are common and their sequelae may have a bearing on post-gastrectomy anaemia. Wells and Kyle (1960) mention oesophagitis as a post-gastrectomy complication and suggest that the cause in most cases is hiatus hernia not always noticed pre-operatively. The patients studied for this paper had had partial gastrectomies, and a high incidence of radiological gastro-oesophageal reflux without hiatus hernia is described.

\section{Clinical Material and Methods}

An unselected group of 61 patients attending for gastric follow-up from 1 to 12 years after operation was studied; 32 had had Billroth I anastomosis and 29 retrocolic Polya operations. All of the resections had been estimated at between $50 \%$ and $60 \%$ of the stomach. The patients were screened by a radiologist and by me. With the gastric fundus full of barium and the patient in the head-down position, gastrooesophageal competence was tested. The patient first rolled from side to side slowly, coughing and straining at intervals, and as a second test of competence a single mouthful of water was swallowed as described by Brombart (1961). Reflux was judged to be significant only if barium refluxed as a wide column into the oesophagus and failed to return to the stomach. Momentary incompetence, when a wisp of barium passed into the lower oesophagus only to be rapidly carried back by the following peristaltic wave, was not thought to be significant. Four of the patients were admitted to hospital for oesophagoscopy and other investigations.

\section{Results}

The results are shown in the Table. The interesting feature is that $50 \%$ of the Billroth I and only $27 \%$ of the Polya cases refluxed. Heartburn, sufficient for the patient to comment on, was present in a significant number of cases. Hiatus hernia was found in 5 of the 32 Billroth I cases, which is much more

\begin{tabular}{|c|c|c|c|}
\hline & & Billroth I & Polya \\
\hline $\begin{array}{l}\text { Total number of cases } \\
\text { Radiological reflux present } \\
\text { Symptoms present } \\
\text { Hiatus hernia present }\end{array}$ & 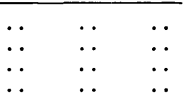 & $\begin{array}{r}32 \\
16 \\
10 \\
5\end{array}$ & $\begin{array}{r}29 \\
8 \\
6 \\
1\end{array}$ \\
\hline
\end{tabular}

than would be expected pre-operatively in this type of patient. Seven patients (four Billroth I and three Polya) complained of heartburn but did not have radiological evidence of reflux.

Four patients (two Polya and two Billroth I) with severe symptoms were admitted for investigation. All four had definite oesophagitis on oesophagoscopy, and bile-stained juices were aspirated from the lower oesophagus when they were in

- Surgical Registrar, Queen Elizabeth Hospital, Birmingham. Present address: Department of Surgery, Harbor General Hospital, 1000 West Carson Street, Torrance, California, U.S.A. the prone position. Only one patient had a hiatus hernia. Although the lowest haemoglobin estimation in these patients was 12.4 g. $/ 100 \mathrm{ml}$., three showed evidence of chronic iron deficiency.

\section{Discussion}

According to Barrett (1952) temporary reflux causes heartburn and continual reflux oesophagitis. That $26 \%$ of these patients had symptoms of heartburn and $30 \%$ radiological reflux suggests that oesophagitis might be present in a considerable number. The accurate diagnosis of oesophagitis necessitates oesophagoscopy, and this has not been thought justifiable in all patients with heartburn. The symptom of heartburn in these patients is thought to be due to reflux of duodenal or jejunal juices into the lower oesophagus. This is not a new concept. Cox (1961) and McKeown (1958) suggested that the cause of the oesophageal strictures in their patients following partial gastrectomy was oesophagitis due to reflux of alkaline afferent-loop contents. Cross and Wangensteen (1951) and
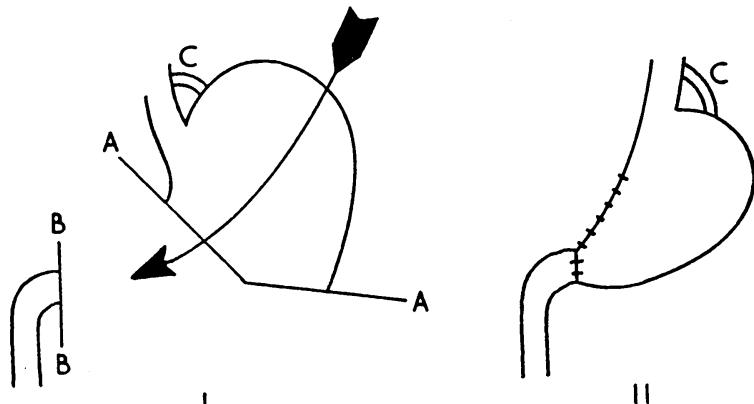

I. $A$ is the line of gastric division, $B$ the line of duodenal division, and $\mathrm{C}$ the gastro-oesophageal angle. The arrow indicates the direction of swing about the cardia which is allowed after division of the left gastric and greater-curve blood-vessels. II. This shows the end-result of the Billroth I partial gastrectomy. The cardia has moved towards the right and the gastro-oesophageal angle has opened out.

Redo et al. (1959) produced oesophagitis under experimental conditions with duodenal juices and bile. In the four cases in this series fully investigated there was bile in the lower oesophagus and oesophagitis was present. The unusual finding is that in only one of these patients was a hiatus hernia demonstrated radiologically, though all four refluxed readily. Gastrooesophageal reflux without demonstrable hiatus hernia has been recorded (Stensrud, 1957 ; Cross et al., 1959 ; Brombart, 1961 ; Atkinson, 1962), but is generally thought to be uncommon.

The cause of reflux in the cases without hiatus hernia is thought to be due to opening out of the gastro-oesophageal angle as a result of dividing the greater-curve vessels and the left gastric artery (Barrett, 1952 ; Collis et al., 1954 ; Atkinson, 1962). The subsequent drawing down of the stomach to make the anastomosis tends to funnel the cardia and allow reflux to take place (see Diagram). A similar but less pronounced effect would be expected after a Polya gastrectomy, when the divided stomach is merely drawn downwards to the jejunum and not swung across to the duodenum. These suggestions correlate with the finding that reflux is more common after Billroth I operations than after Polya resections. The funnelled 
cardia may well lead to the development of a hiatus hernia and account for the high incidence of this condition in the Billroth I group.

A further possible explanation of the findings is that there is a reduction in tone of the intrinsic sphincter mechanism of the lower oesophagus after partial gastrectomy. Clark and Vane (1961) showed that in animals the presence of alkali in the lower oesophagus reduces the tone in this sphincter, and it is thought that alkali in the oesophagus of post-gastrectomy patients reduces the efficiency of the gastro-oesophageal closing mechanism still further.

Stammers and Williams (1963) have pointed out that iron absorption after partial gastrectomy is adequate for normal needs provided there is no occult loss. An attempt was made to correlate anaemia with radiological reflux. Iron deficiency and anaemia were present in as many patients with reflux as in those without, and no significant conclusions could be drawn from this small series. A more detailed study is planned to clarify this point. It is suggested, however, that oesophagitis after partial gastrectomy is a much more common condition than hitherto recognized and is a possible cause of loss of blood in the post-gastrectomy patient.

\section{Summary}

Sixty-one unselected patients were investigated after partial gastrectomy, and heartburn was found to be a complaint in 16 of them. Radiological reflux was induced in 24 patients$50 \%$ of the Billroth I and $27 \%$ of the Polya cases. Hiatus hernia was present in only six patients. It is suggested that the symptoms are due to alkaline reflux with tryptic digestion of the oesophageal mucosa, and a mechanism is suggested for its causation.
An attempt to correlate the symptoms of oesophagitis with post-gastrectomy anaemia was unsuccessful, though this is thought to be a likely association.

I would like to thank the following for their help and encouragement in this work: Mr. J. Leigh Collis and Mr. D. M. Morrissey, consultant surgeons to the Queen Elizabeth Hospital, Birmingham, and Mr. J. A. Williams, consultant surgeon to the General Hospital, Birmingham. I also thank Dr. M. Atkinson, consultant physician to Worcester Royal Infirmary, for reading the manuscript of this paper and making some valuable suggestions. Finally, I wish to thank Dr. O. E. Smith, consultant radiologist to the Queen Elizabeth Hospital, Birmingham, and Dr. J. C. Bishop, consultant radiologist to the General Hospital, Birmingham, for allowing me facilities in their departments for screening the patients.

\section{REFERENCES}

Atkinson, M. (1962). Gut, 3, 1.

Barrett, N. R. (1952). Proc. roy. Soc. Med., 45, 279.

Benedict, E. B. (1960). Gastroenterology, 39, 285.

Bingham, J. A. W. (1958). Brit. med. F., 2, 817.

Brombart, M. (1961). Clinical Radiology of the Oesophagus, p. 86. Wright, Bristol.

Clark, C. G., and Vane, J. R. (1961). Gut, 2, 252.

Collis, J. L., Kelly, T. D., and Wiley, A. M. (1954). Thorax, 9, 175.

Cox, K. R. (1961). Brit. F. Surg., 49, 307.

Cross, F. S., Smith, G. V., jun., and Kay, E. B. (1959). F. thorac cardiovasc. Surg., 38, 798.

- and Wangensteen, O. H. (1951). Proc. Soc. exp. Biol. (N.Y.), 77, 862.

Mckeown, K. C. (1958). Brit. med. 7., 2, 819.

Redo, S. F., Barnes, W. A., and Ortiz de la Sierra, A. (1959). Ann. Surg., 149, 556.

Stammers, F. A. R., and Williams, J. A. (1963). Partial Gastrectomy, p. 154. Butterworths, London.

Stensrud, N. (1957). ₹. thorac. cardiovasc. Surg., 33, 749.

Wells, C. A., and Kyle. J. (1960). Peptic Ulceration, p. 139. Livingstone, Edinburgh and London.

\title{
Laboratory Evaluation of a New Antibiotic-Cephaloridine (Ceporin)
}

\author{
P. W. MUGGLETON,* B.SC., PH.D. ; CYNTHIA H. O'CALLAGHAN,* B.sC., M.sc. ; \\ W. K. STEVENS,* F.I.M.L.T., M.I.BIOL.
}

Brit. med. F., 1964, 2, 1234-1237

Cephaloridine (Ceporin: Glaxo Ltd.) is a semisynthetic antibiotic, 7-[(2-thienyl)acetamido]-3-(1-pyridylmethyl)-3-cephem4-carboxylic acid betaine. It is produced chemically from cephalosporin $\mathrm{C}$ by replacing the $\alpha$-aminoadipic side-chain at position 7 by 2 -thienylacetic acid and the acetoxy group at position 3 by pyridine. It has the following structure:

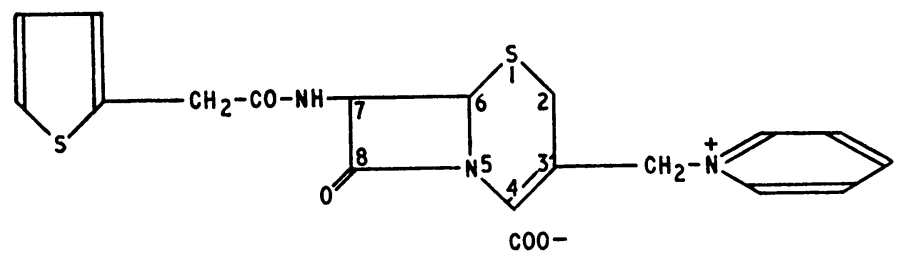

The natural antibiotic, cephalosporin C, from which cephaloridine is derived, is produced by a strain of the mould Cephalosporium acremonium, which was isolated by Brotzu (1948) ; its structure was elucidated by Abraham and Newton

* Glaxo Research Ltd., Stoke Poges, Bucks, and Greenford, Middlesex.
(1961). Though it is stable to acid and to penicillinase and is equally active against Gram-positive and Gram-negative organisms, its intrinsic activity is relatively low.

Replacement of the 7- $\alpha$-aminoadipic acid side-chain of cephalosporin $\mathrm{C}$ with various substituted acetic acids gives compounds showing a marked increase in activity against Staphylococcus aureus and other Gram-positive organisms, but this type of substitution in general renders the acetoxy group at position 3 far more labile in the mammalian body (O’Callaghan and Muggleton, 1963).

When the acetoxy group of cephalosporin $C$ is replaced with pyridine or its analogues the resulting compounds have increased antibacterial activity (Hale, Newton, and Abraham, 1961) and are, moreover, stable in the body (O'Callaghan and Muggleton, 1963).

Many analogues of cephalosporin $C$ have been prepared in which both the $\alpha$-aminoadipic acid side-chain and the acetoxy group have been replaced. They have been examined for their possible therapeutic use. One with considerable potential usefulness is cephaloridine; its properties are reported here. 